\title{
Pancreatitis in children
}

\section{A study in the North of England}

\author{
J. R. SIBERT \\ From the Department of Child Health, University of Newcastle upon Tyne
}

\begin{abstract}
Sibert, J. R. (1975). Archives of Disease in Childhood, 50, 443. Pancreatitis in children: a study in the North of England. Cases of pancreatitis in children in the Newcastle Regional Board area were studied over approximately 6 years. There were 9 cases aged between 6 weeks and 15 years. In 5 children (all under 7 years of age) likely aetiological factors were found ( 2 cases of mumps and 1 case each due to trauma, measles, and hereditary pancreatitis). In 4 children all over 13 years of age no likely aetiological factor was found. It is speculated that they may represent one end of the age spectrum of idiopathic pancreatitis as it occurs in adults. Hereditary pancreatitis was definitely found in only one child and possibly in one other. Therefore, it probably does not represent the major cause of pancreatitis in children as has been previously thought. One child died, but all the other children have thrived since their illness.
\end{abstract}

Pancreatitis seems to be an uncommonly recognized condition in childhood. Undoubtedly it occurs less frequently in children than adults. Alcohol, which is a major cause of the disease in adults (James, Agnew, and Bouchier, 1974), has little or no part in the aetiology of the disease in childhood. Hereditary pancreatitis, first reported by Comfort and Steinberg (1952), is now a wellrecognized condition in the United States (Kattwinkel et al., 1973), and to a lesser extent in Great Britain (Sibert, 1973). This condition occurs in children and young adults and seems to occur only rarely over the age of 40 years (Sibert, 1975). It has been thought to be a major cause of pancreatitis in children (Kattwinkel et al., 1973).

The majority of published reports on pancreatitis in childhood have been single cases, and there have been few attempts to analyse its aetiological background. Dobbs (1935) reported one case, and reviewed 14 published cases at that time. Hendren, Greep, and Patton (1965) reviewed 15 cases from their surgical experience in Boston, Massachusetts over 9 years. Frey and Redo (1963) reviewed 18 cases from New York. 4 of these survived (2 had mumps and the others gallstones and an annular pancreas) but the remaining 14 cases were diagnosed at necropsy and in many pancreatitis was not the major cause of death.

Received 15 November 1974.
Because of this background, cases of pancreatitis in children under 16 in the Newcastle Regional Board area were studied over approximately 6 years (1967-73) to ascertain how frequently the disease occurs and is recognized in a known population, to ascertain its aetiological background in Great Britain, and to see how common hereditary pancreatitis is in a British population.

\section{Materials and methods}

The hospital case record numbers of cases of pancreatitis occurring under the age of 16 years in the Newcastle Regional Hospital Board area were obtained from the Hospital Activity Analysis of the Statistics Department of the Board (Mr. R. A. McNay). This analysis was gradually introduced from 1965 onwards, and covered the whole Regional Board area by 1968. The Newcastle Regional Board area covered Northumberland, Durham, Cumberland, and parts of North Yorkshire and Westmorland, with a child population of 765000 (0-14 years) (Health and Personal Social Services Statistics for England, 1973). The consultant in charge of each case was contacted and permission asked to study the case notes and to visit the family and child.

A full history was taken, including a full family history of pancreatitis and abdominal pain going back at least 3 generations. If no aetiological factor seemed likely, blood was taken for calcium and lipoprotein electrophoresis. There were 9 cases under the age of 16 years revealed by this study. 


\section{Case reports (Table I)}

Case 1. Aged 6 weeks. Admitted in 1968 to the Middlesbrough General Hospital with a history of 24-hour cough and cold ${ }_{2}$ crying all night, and some vomiting. On examination he was afebrile but his abdomen was distended with a brownish discoloration around the umbilicus. Because of the distension, laparotomy was performed. There were large quantities of fluid in the abdomen, without evidence of obstruction. The pancreas was oedematous and inflamed.

Postoperatively he made an uneventful recovery, apart from developing a left-sided parotid swelling 10 days after the start of the illness. A haemabsorbing virus, probably a mumps virus, was isolated from nose and throat swab. He has thrived since, and is well 5 years later. There is no family history of significant abdominal pain ( 3 generations, 43 members).

Conclusion. Acute pancreatitis probably due to mumps.

Case 2. Female aged $2 \frac{1}{2}$ years. This little girl from poor social circumstances was admitted to the Queen Elizabeth Hospital in Gateshead with a 2-day history of nonspecific illness including cough, vomiting, and anorexia. She had fallen over a tricycle 3 days before and the handlebar had injured the abdomen.

On admission the abdomen was slightly distended, with some bluish discolouration. It was rigid without bowel sounds. Because of these findings laparotomy was performed. This showed haemorrhagic fluid with normal abdominal organs. There was a collection of haemorrhagic fluid in the lesser sac and fat necrosis on the omentum and peritoneum. Postoperative course was uneventful and investigations included a normal serum calcium, a glucose tolerance curve, and I.V. cholangiogram.

There was no family history of significant abdominal pain ( 3 generations, 15 members). She has been free of abdominal pain since this episode.

Conclusion. Acute pancreatitis probably secondary to trauma.

Case 3. Female aged 5 years. Admitted to Newcastle General Hospital with abdominal pain twice in 1972 and twice in 1973. During the first admission this proved to be pancreatitis at laparotomy. 9 relatives with definite pancreatitis and 15 family members suspected of having the disease have been found and have been described in detail in 1973 (Sibert, 1973).

Conclusion. Recurrent pancreatitis (hereditary).

Case 4. Male aged 5 years. Admitted to the Royal Victoria Infirmary, Newcastle upon Tyne, with a 4-day history of swelling and pain in both parotid regions, and a 2-day history of persistent vomiting and anorexia. On examination he had clinical mumps and was mildly dehydrated. There was mild abdominal tenderness. Serum amylase was raised at 135 Wohlgemuth units $/ 100 \mathrm{ml}$; calcium $8.3 \mathrm{mg} / 100 \mathrm{ml}$. A diagnosis of mumps pancreatitis was made and intravenous fluids given for 24 hours. The vomiting settled and he was discharged 3 days after admission.

\section{Conclusion. Acute pancreatitis due to mumps.}

Case 5. Female aged 6 years. Admitted to Sunderland Children's Hospital in 1970 with a 30-hour history of abdominal pain and vomiting. 9 days previously she had had clinical measles. On examination she had the remains of a measles rash, and there was abdominal tenderness maximum in the epigastrium but also on the right side. At laparotomy free peritoneal fluid with fat necrosis on omentum and peritoneum was

TABLE I

Synopsis of findings in 9 cases of pancreatitis in childhood

\begin{tabular}{|c|c|c|c|c|c|c|c|c|}
\hline Case no. & In whose care & Age & ? Pain & ? Vomiting & $\begin{array}{l}\text { ? Pseudo- } \\
\text { cyst }\end{array}$ & Type & $\begin{array}{l}\text { Diagnosis } \\
\text { made by }\end{array}$ & Aetiology \\
\hline 1 & $\begin{array}{l}\text { Paediatrician }+ \\
\text { surgeon }\end{array}$ & $6 w$ & Probably & Yes & No & Acute & Laparotomy & Mumps \\
\hline 2 & Paediatrician + & $2 \frac{1}{2}$ yrs & Probably & Yes & Yes & Acute & Laparotomy & Trauma \\
\hline 3 & $\begin{array}{l}\text { Paediatrician }+ \\
\text { surgeon }\end{array}$ & $5 y r s$ & Yes & Yes & No & Relapsing & $\begin{array}{l}\text { Laparotomy } \\
\text { and amylase }\end{array}$ & Hereditary \\
\hline $\begin{array}{l}6 \\
7\end{array}$ & $\begin{array}{l}\text { Surgeon } \\
\text { Surgeon }\end{array}$ & $\begin{array}{l}13 y r s \\
14 y r s\end{array}$ & $\begin{array}{l}\text { Yes } \\
\text { Yes }\end{array}$ & $\begin{array}{l}\text { Yes } \\
\text { Yes }\end{array}$ & $\begin{array}{l}\text { Probably } \\
\text { Yes }\end{array}$ & $\begin{array}{l}\text { Acute } \\
\text { Acute }\end{array}$ & Amylase & $\begin{array}{l}\text { Idiopathic } \\
\text { Idiopathic }\end{array}$ \\
\hline 8 & $\begin{array}{c}\text { Physician + } \\
\text { surgeon }\end{array}$ & $14 y r s$ & Yes & Yes & Yes & $\begin{array}{l}\text { Acute } \\
\text { relap- }\end{array}$ & $\begin{array}{c}\text { Amylase }+ \\
\text { laparotomy }\end{array}$ & Idiopathic \\
\hline 9 & Surgeon & $15 y r s$ & Yes & Yes & No & $\begin{array}{l}\text { ? Acute } \\
\text { relap- } \\
\text { sing }\end{array}$ & Amylase & $\begin{array}{l}\text { Idiopathic } \\
\text { ? Heredit- } \\
\text { ary }\end{array}$ \\
\hline
\end{tabular}


found. The appendix was normal. The diagnosis of pancreatitis made at laparotomy was confirmed by a raised serum amylase ( 35 Wohlgemuth units $/ 100 \mathrm{ml}$ ). 3 days after admission the pain resolved and she has thrived since.

Serology showed a measles titre of $1 / 640$ in both acute and convalescent sera, and Herpes simplex titre 1/5 in acute and 1/80 in convalescent sera. There was no family history of significant abdominal pain ( 3 generations, 14 members).

Conclusion. Acute pancreatitis probably secondary to measles.

Case 6. Female aged 13 years. Admitted to the Bensham General Hospital, Grateshead, in 1973 with a 14-day history of abdominal pain and distension with persistent vomiting. On examination, she was ill with abdominal distension and generalized tenderness. There was a mass in the epigastrium. Serum amylase was raised at 128 Wohlgemuth units, and a diagnosis of pancreatitis was made. Plasma urea was $100 \mathrm{mg} /$ $100 \mathrm{ml}$, plasma sodium $117 \mathrm{mEq} / 1$, and plasma chloride $79 \mathrm{mEq} / \mathrm{l}$. There was bilateral basal shadowing on chest $x$-ray and dilated small bowel but no fluid levels on abdominal $x$-ray. She was treated with intravenous fluids, antibiotics, and aprotinin but she deteriorated and died 3 days after admission. Permission for necropsy was refused. Because of the possible distress it might cause so soon after this episode no family history was taken; however, her general practitioner was unaware of any suggestive history.

Conclusion. Acute fatal pancreatitis without obvious cause.

Case 7. Male aged 14 years. Admitted to the Ryhope General Hospital, Sunderland, in 1971 with a 3-day history of central abdominal pain. He had sufferred from intermittent attacks of similar, but less severe pain for a year previously. These occurred approximately every 6 weeks, lasted 2-3 days, and were associated with vomiting.

On examination on admission there was upper abdominal tenderness and rigidity. The diagnosis of pancreatitis was made on a raised serum amylase (115 Wohlgemuth units $/ 100 \mathrm{ml}$ ). The pain resolved in 5 days. 2 weeks later he had a further attack of pain. Serum amylase was 36 Wohlgemuth units $/ 100 \mathrm{ml}$ and a mass was palpable in the epigastrium. Barium meal showed a deformity of the stomach characteristic of a pancreatic pseudocyst, and this was confirmed at laparotomy. A posterior gastrocystostomy was made. Glucose tolerance test was normal and he was discharged 2 weeks after operation. He has been well since and is now working. There was no history of alcohol, trauma, nor a significant family history of abdominal pain (4 generations, 56 members). Serum lipoprotein electrophoresis and serum calcium were both normal.

Conclusion. Acute idopathic pancreatitis (with possibility that he had previous attacks).
Case 8. Female aged 14 years. Started getting attacks of central abdominal pain in 1969. She had 6 attacks in 1970, during one of which she was admitted to Hartlepool General Hospital. A moderate number of pus cells were found in her urine, and she was treated for a urinary infection. Her pains continued and in 1972 she was admitted with a history of central abdominal pain radiating to the loins, anorexia, and vomiting. She was mildly jaundiced (bilirubin $3 \cdot 8$ $\mathrm{mg} / 100 \mathrm{ml}$ ), and serum amylase was normal at 5 Wohlgemuth units $/ 100 \mathrm{ml}$. Bilirubin fell to normal on the 4th day of admission. However, serum amylase was marginally raised at 20 Wohlgemuth units $/ 100 \mathrm{ml}$ on the 7th day. She ran an intermittent fever which settled on ampicillin. She was thought to have cholangitis.

Two months later she was admitted with further similar pain, and at laparotomy she had a large pancreatic pseudocyst. A transgastro-cystogastrotomy was performed. She has always been an obese girl and the first admission in 1972 coincided with a severe diet. There is no history of significant abdominal pain in the family (4 generations, 37 members). Serum lipoprotein electrophoresis and serum calcium were both normal.

Conclusion. Idiopathic pancreatitis probably of relapsing type. There is a possibility that an attack might have been precipitated by dieting.

Case 9. Male aged 15 years, III. 6 on family tree (Fig.). Admitted to Newcastle General Hospital in 1972 with a 12-hour history of central abdominal pain. On examination there was central abdominal tenderness. A diagnosis of pancreatitis was made on a raised serum amylase (1200 Somogyi units $/ 100 \mathrm{ml}$ ). He was treated with analgesics and intravenous fluid, and his pain settled over 4 days. He had a similar attack of pain when aged 9 years lasting 4-5 days, and another when aged 12 years lasting 2 days. Serum calcium was normal. He has remained free of pain since 1972 and is now a student.
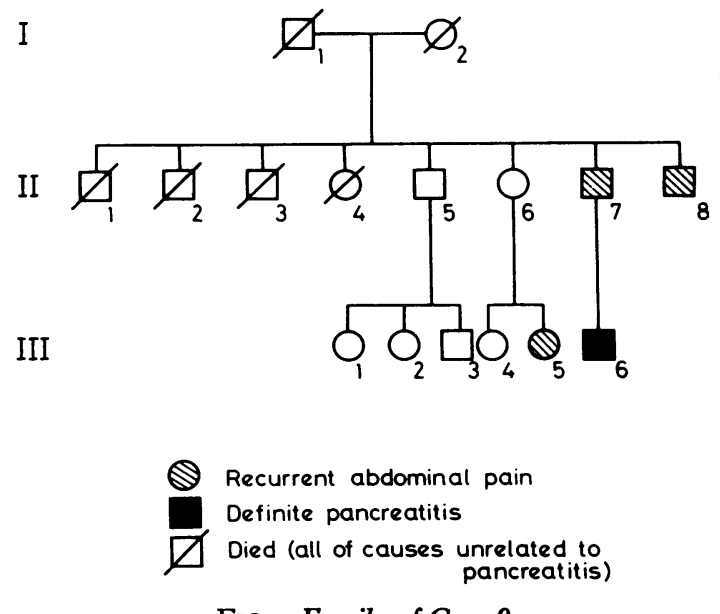

Fig.-Family of Case 9 
His father (II.7 in Fig.) is 52 years of age. He had intermittent attacks of epigastric and central abdominal pain lasting several days in his late teenage years. There was some vomiting and the attacks occurred several months apart. They had been diagnosed as gallstones by a general practitioner during the Second World War. At age 27 years he had a severe attack of pain and consulted a surgeon after the pain had resolved. A 'cold' appendicectomy was performed; however, he continued to have the attacks, which then resolved when he was aged 30 years without further trouble. $X$-ray of abdonien showed calcification which was in the right kidney (on intravenous pyelogram) not in the pancreas. Serum calcium was normal.

An uncle (II.8) had several attacks of epigastric pain when a child and young adult, which have since resolved. No cause could be found for these. The only other member (III.5) of the family who suffers from abdominal pain is a female cousin whose pain is lower abdominal and premenstrual. It does not sound pancreatic in nature. The mother of Case 9 is free from abdominal pain. It is interesting to note that the families of Cases 5 and 9 both originate from the Bishop Auckland area of County Durham, and may therefore be distantly related.

Conclusion. Acute idiopathic pancreatitis with the possibility of previous attacks and possibility of hereditary pancreatitis. The father's history would do well for pancreatitis, and the fact that the pain settled when he was 30 years old is typical of hereditary pancreatitis. Nevertheless, the renal calcification on $x$-ray suggests the possibility that the father had renal colic. The father himself thought his son's pain was like his own.

\section{Discussion}

It is clear from this survey that pancreatitis in childhood is an uncommonly recognized condition, with a frequency of recognition approximately 1 in
500000 per year. This is almost certainly an underestimate of its true frequency. Cases are likely to go undiagnosed and be put together with the numerous children admitted to hospital with abdominal pain which clear up without treatment, and on whom no diagnosis is made. Indeed, from work with the family of Case 3 it is known that one child in Hartlepool has had pancreatitis in the period in question; however, the diagnosis has only recently been made (Sibert, 1975).

One child died of pancreatitis in the series, a fact that emphasizes the potentially serious nature of the disease. Nevertheless, all the other children seemed to have thrived after their illness, and in 3 of them (Cases 2, 3, and 8) obesity is a problem. Though no formal malabsorption studies were made, all the children's stools were normal in appearance. There was no diabetes in the children and glucose tolerance tests when done were normal. Pseudocyst formation was common and occurred in 4 out of the 9 cases. The children's ages ranged from the neonatal period to the teenage years (Table II).

Mumps is a well recognized cause. However, Eagles (1947) found only 3 cases of pancreatitis in 1664 cases of mumps in young adults, the diagnosis being based on symptoms and signs only. In this series 2 children had mumps, one aged 6 weeks and one older child. This probably underestimates the true incidence of mumps pancreatitis in the community as mild cases may not be admitted to hospital. Other virus infections have been implicated less frequently. In this series one girl had pancreatitis after measles (Case 5) and pancreatitis has been reported as part of the congenital rubella syndrome (Bunnell and Monif, 1972). Coxsackie $B$ virus infections have also caused

TABLE II

Aetiological factors in pancreatitis in children in this and previous series

\begin{tabular}{|c|c|c|c|c|}
\hline Aetiological factors & $\begin{array}{l}\text { This } \\
\text { series }\end{array}$ & $\begin{array}{l}\text { Dobbs } \\
(1935)\end{array}$ & $\begin{array}{l}\text { Hendren, } \\
\text { Greep, and } \\
\text { Patten } \\
(1965)\end{array}$ & $\begin{array}{c}\text { Frey and } \\
\text { Redo } \\
(1963)\end{array}$ \\
\hline $\begin{array}{l}\text { Total } \\
\text { Mumps } \\
\text { Hereditary } \\
\text { Trauma } \\
\text { Other virus infections (i.e. Coxsackie, rubella, measles) } \\
\text { Idiopathic } \\
\text { Ascaris lumbricoides } \\
\text { Gallstones } \\
\text { Structural abnormalities of pancreatic ducts } \\
\text { Malnutrition } \\
\text { Steroid therapy } \\
\text { Cystic fibrosis } \\
\text { Hyperlipoproteinaemia (Type I or V) } \\
\text { Hypercalcaemia (hereditary hypoparathyroidism) }\end{array}$ & $\begin{array}{l}9 \\
2 \\
1 \\
1 \\
1 \\
4 \\
0 \\
0 \\
0 \\
0 \\
0 \\
0 \\
0 \\
0\end{array}$ & $\begin{array}{r}15 \\
0 \\
0 \\
3 \\
0 \\
8 \\
3 \\
1 \\
0 \\
0 \\
0 \\
0 \\
0 \\
0\end{array}$ & $\begin{array}{r}15 \\
1 \\
1 \\
2 \\
0 \\
5 \\
0 \\
1 \\
4 \\
1 \\
0 \\
0 \\
0 \\
0\end{array}$ & $\begin{array}{r}18 \\
2 \\
0 \\
0 \\
0 \\
3 \\
0 \\
1 \\
3 \\
6 \\
3 \\
0 \\
0 \\
0\end{array}$ \\
\hline
\end{tabular}


pancreatitis both in infants (Fechner, Smith, and Middelkamp, 1963) with myocarditis and encephalitis, and also in adults (Ursing, 1973). Acute pancreatitis with acute encephalopathy has been described in children (Stover, Wanglee, and Kennedy, 1968).

Hereditary pancreatitis has been thought to be one of the major causes of pancreatitis in childhood (Kattwinkel et al., 1973). Those who have investigated families with this condition have found many patients with recurrent abdominal pain in whom the diagnosis was not suspected. Nevertheless, in this present series only one patient definitely had hereditary pancreatitis, and one other was suspected of having relatives with the disease, and therefore the majority of children with pancreatitis do not appear to have hereditary aetiological factors operating. Hereditary pancreatitis has been described in many families in the United States with British origins, though it has only been described in 3 families in Britain. It is therefore likely that it has been underdiagnosed in this country.

Abdominal trauma is known to cause acute pancreatitis, often with pseudocyst formation. Dobbs (1935), in his review of published cases, found 3 cases out of a total of 15 . Recently, pancreatitis has been described in child abuse (Pena and Medovy, 1973) as well as in accidental trauma. In one patient in this series, pancreatitis was probably due to trauma (Case 2).

Familial lipaemia has been described as causing pancreatitis in childhood (Kennedy and Collett 1949; Poulsen, 1950). It is now clear that the forms of lipaemia involved are type I and type V hyperlipoproteinaemia (Fredrickson and Levy, 1972). However, it is noteworthy that patients with type I hyperlipoproteinaemia suffer from attacks of acute abdominal pain without having pancreatitis. Children treated with corticosteroids were first noted to have attacks of pancreatitis by Baar and Wolff in 1957 when they described 2 cases. Further cases were described in 1968 (Riemenschneider, Wilson, and Vernier, 1968).

Patients with cystic fibrosis occasionally have attacks of abdominal pain due to pancreatitis (Shwachman, Lebenthal, and Khan, 1973). Hereditary hyperparathyrodism has been described with pancreatitis (Jackson, 1958; Carey and Fitzgerald, 1968). This is more usual in adults; however, some patients are in the upper paediatric age range. It is difficult to be certain whether these patients have pancreatitis secondary to hypercalcaemia, or whether they have hereditary pancreatitis in addition to hereditary hyperparathyroidism. Mal- nutrition was thought to be an aetiological factor in the 4 cases of pancreatitis described from Africa in post-mortem material by Collins (1958) and was thought to be a factor in 6 cases of Frey and Redo's series (1963) (also based on necropsies). One child in the present series had pancreatitis when on a diet for obesity.

Obstruction of the pancreatic duct for various causes has been implicated in the aetiology of pancreatitis in childhood. Dobbs, reviewing published cases in 1935, found 3 reports of pancreatitis in children secondary to Ascaris lumbricoides. Gallstones, a relatively common factor causing pancreatitis in adults, has rarely been described in children (Dobbs, 1935; Hendren et al., 1965; Frey and Redo, 1963). Hendren et al. thought that 3 of their patients had evidence of stenosis of the ampulla of Vater, one of which had hereditary pancreatitis.

Many cases of pancreatitis in children have been reported where no aetiological factor appears to apply including those of Haigh (1956) and Vernon, Stening, and Smith (1970). Howat (1968) found 4 out of 54 cases of chronic pancreatitis had begun before the age of 20 years. In the present series the children on whom there was no likely aetiological factor operating were all aged under 7 years, and those on whom no definite factor was found were all over 13 years of age. It may be that the older children represent one end of the age spectrum of idiopathic pancreatitis as it is found in adults. Most children who have pancreatitis have acute pancreatitis. Those who have recurrent attacks either have hereditary pancreatitis, type I hyperlipoproteinaemia, hereditary hyperparathyroidism, cystic fibrosis, or are idiopathic.

Pancreatitis in children has probably been underdiagnosed in the past. It should, therefore, be suspected in abdominal pain in childhood where no other diagnosis seems likely. This can usually be done in an acute attack, as in adults, by measuring serum amylase.

I thank Drs. J. Angus, Christine Cooper, R. H. Jackson, A. Lillington, R. W. B. White, and Mr. A. Petty and Mr. D. A. Samford for permission to study patients under their care; and Mr. R. A. McNay and staff of the Statistics Department of the Northern Regional Health Authority.

\section{REFERENCES}

Baar, H. S., and Wolff, O. H. (1957). Pancreatic necrosis in cortisone-treated children. Lancet, 1, 812.

Bunnell, C. E., and Monif, G. R. G. (1972). Interstitial pancreatitis: in the congenital rubella syndrome. Fournal of Pediatrics, 80, 465.

Carey, M. C., and Fitzgerald, O. (1968). Hyperparathyroidism associated with chronic pancreatitis in a family. Gut, 9, 700.

Collins, J. (1958). Pancreatitis in young children. Archives of Disease in Childhood, 33, 432. 
Comfort, M. W., and Steinberg, A. G. (1952). Pedigree of a family with hereditary chronic relapsing pancreatitis. Gastroenterology, 21, 54.

Dobbs, R. H. (1935). Acute pancreatitis in childhood. Lancet, 2, 989.

Eagles, A. Y. (1947). Analysis of a four year epidemic of mumps. Archives of Internal Medicine, 80, 374.

Fechner, R. E., Smith, M. G., and Middelkamp, J. N. (1963) Coxsackie B virus infection of the newborn. American fournal of Pathology, 42, 493.

Fredrickson, D. S., and Levy, R. I. (1972). Familial hyperlipoproteinemia. Metabolic Basis of Inherited Disease, 3rd ed., p. 545. Edited by J. B. Stanbury, J. B. Wyngaarden, and D. S. Fredrickson. McGraw Hill, New York.

Frey, C., and Redo, S. F. (1963). Inflammatory lesions of the pancreas in infancy and childhood. Pediatrics, 32, 93.

Haigh, E. (1956). Acute pancreatitis in childhood. Archives of Disease in Childhood, 31, 273.

Health and Personal Social Services Statistics for England (1973) p. 13. H.M.S.O., London.

Hendren, W. H., Greep, J. M., and Patton, A. S. (1965). Pancreatitis in childhood. Experience with 15 cases. Archives of Disease in Childhood, 40, 132.

Howat, H. T. (1968). Chronic pancreatitis. Medical Aspects. Postgraduate Medical fournal, 44, 733.

Jackson, C. E. (1958). Hereditary hyperparathyroidism associated with recurrent pancreatitis. Annals of Internal Medicine, 49, 829.

James, O., Agnew, J. E., and Bouchier, I. A. D. (1974). Chronic pancreatitis in England; a changing picture? British Medical Fournal, $2,34$.

Kattwinkel, J., Lapey, J., di Sant'Agnese, P. A., and Edwards, W. A.
(1973). Hereditary pancreatitis. Three new kindreds and a critical review of the literature. Pediatrics, 51, 55 .

Kennedy, R. L. J., and Collett, R. W. (1949). Chronic relapsing pancreatitis and hyperlipemia. American fournal of Diseases of Children, 78, 80.

Pena, S. D. J., and Medovy, H. (1973). Child abuse and traumatic pseudocyst of the pancreas. Fournal of Pediatrics, 83, 1026.

Poulsen, H. M. (1950). Familial lipaemia. Acta Medica Scandinavica, 138, 413.

Riemenschneider, T. A., Wilson, J. F., and Vernier, R. L. (1968) Glucocorticoid-induced pancreatitis in children. Pediatrics, 41, 428.

Shwachman, H., Lebenthal, E., and Khan, K. T. (1973). Acute attacks of pancreatitis in patients with cystic fibrosis. (Abst.) 4th Annual Meeting European Working Group for Cystic Fibrosis, p. 24. Polish Paediatric Association, Warsaw.

Sibert, J. R. (1973). Hereditary pancreatitis in a Newcastle family. Archives of Disease in Childhood, 48, 618.

Sibert, J. R. (1975). A British family with hereditary pancreatitis. Gut, 16,81 .

Stover, S. L., Wanglee, P., and Kennedy, C. (1968). Acute hemorrhagic pancreatitis and other visceral changes associated with acute encephalopathy. Fournal of Pediatrics, 73, 235.

Ursing, B. (1973). Acute pancreatitis in Coxsackie B infection. British Medical fournal, 3, 524.

Vernon, J. K., Stening, F., and Smith, R. (1970). Chronic relapsing pancreatitis in childhood. British Fournal of Surgery, 57, 906.

Correspondence to Dr. J. R. Sibert, Department of Child Health, University Hospital of Wales, Heath Park, Cardiff CF4 4XW. 